NBER WORKING PAPER SERIES

\title{
THE RELATION BETWEEN MANAGED CARE MARKET SHARE AND THE TREATMENT OF ELDERLY FEE-FOR-SERVICE PATIENTS WITH MYOCARDIAL INFARCTION
}

\author{
Paul A. Heidenreich \\ Mark McClellan \\ Craig Frances \\ Laurence C. Baker \\ Working Paper 8065 \\ http://www.nber.org/papers/w8065 \\ NATIONAL BUREAU OF ECONOMIC RESEARCH \\ 1050 Massachusetts Avenue \\ Cambridge, MA 02138 \\ January 2001
}

Dr. Heidenreich is supported by a Career Development Award from the Veterans Affairs Health Services Research and Development Service. The analysis upon which this publication is based were performed under Contract number 500-96-P535, entitled "Utilization and Quality Control Peer Review Organization for the State of California," sponsored by the Health Care Financing Administration (HCFA), Department of Health and Human Services. The content of this publication does not necessarily reflect the views or policies of the Department of Health and Human Services, nor does mention of trade names, commercial products, or organizations imply endorsement by the U.S. Government. The author assumes full responsibility for the accuracy and completeness of the ideas presented. This article is a direct result of the Health Care Quality Improvement Program initiated by HCFA, which has encouraged identification of quality improvement projects derived from analysis of patterns of care, and therefore required no special funding on the part of this Contractor. Ideas and contributions to the author concerning experience in engaging with issues presented are welcomed. The views expressed herein are those of the authors and not necessarily those of the National Bureau of Economic Research.

(C) 2001 by Paul A. Heidenreich, Mark McClellan, Craig Frances, and Laurence C. Baker. All rights reserved. Short sections of text, not to exceed two paragraphs, may be quoted without explicit permission provided that full credit, including (C) notice, is given to the source. 
The Relation Between Managed Care Market Share and the Treatment of Elderly Fee-For-Service Patients with Myocardial Infarction.

Paul A. Heidenreich, Mark McClellan, Craig Frances, and Laurence C. Baker

NBER Working Paper No. 8065

January 2001

JEL No. I1

\begin{abstract}
Managed care may affect medical treatments for non-managed-care patients if it alters local market structure or physician behavior. We investigate whether higher levels of overall managed care market share are associated with greater use of recommended therapies for fee-for-service patients with acute myocardial infarction using data on 112,900 fee-for-service Medicare beneficiaries residing in one of 320 metropolitan statistical areas, with age $\geq 65$ years, and admitted with an acute myocardial infarction between February 1994 and July 1995 from the Cooperative Cardiovascular Project. After adjustment for patient characteristics, severity of illness, characteristics of the hospital of admission, specialty of treating physicians, and other area characteristics, patients treated in areas with high levels of managed care had greater relative use of $\beta$-blockers during hospitalization and at discharge and aspirin during hospitalization and at discharge, consistent with more appropriate care. Patients in high HMO areas may be less likely to receive angiography when compared to areas with low levels of managed care, although this result was only marginally significant. In unadjusted comparisons, patients in high HMO market share areas had lower 30 day mortality, but there were no differences in 30 day mortality when all of the control variables were included in the model. We conclude that managed care can have widespread effects on the treatment of patients and the quality of care they receive, even for patients not enrolled in managed care organizations.
\end{abstract}

Paul Heidenreich, M.D., M.S.

111C Cardiology

Palo Alto VA Medical Center

3801 Miranda Avenue

Palo Alto, CA 94304

Tel. (650) 493-5000-64069

Fax (650) 852-3473

Email: pah@smi.stanford.edu

Laurence Baker

Department of Health Research and Policy

HRP Redwood Building, Rm. 253

Stanford University

Stanford, CA 94305-5405

and NBER
Mark McClellan

Department of Economics

Stanford University

Stanford, CA 94305

and NBER

Craig Frances

Veterans Affairs San Francisco Medical Center San Francisco, CA 


\section{Introduction}

The growth in managed care in the United States is likely to have affected the delivery of medical care.(1) These effects can occur both directly to patients enrolled in managed care plans, and indirectly ("spillover" effects) to patients with fee-for-service insurance who reside in areas of high managed care activity. Past studies indicate that spillover effects of managed care have occurred. Feefor-service patients residing in areas with high managed care activity have been shown to have lower overall Medicare expenditures than patients residing in areas with less managed care.(2) Areas with high managed care activity have also been shown to have lower availability and use of new technologies (3, 4) and lower overall hospital costs.(5)

The spillover effects of managed care may occur by several mechanisms. Health care providers who take care of patients in managed care plans will likely make treatment decisions based in part on incentives and restrictions provided by the managed care organization. If these providers also treat feefor-service patients they may treat them similarly preferring to treat all patients equally, rather than altering their care based on different methods of reimbursement. In addition, interaction between managed care and non-managed care providers may lead to similar care for managed care and fee-forservice patients.(6)

Previous work has reported that acute MI patients enrolled in managed care organizations receive care that is more in compliance with recommended therapies and process of care measures than care for fee-for-service patients.(7, 8) We hypothesized that high levels of local managed care activity will also affect the care of non-enrolled patients. To address this, we examined the effects of managed care on recommended treatments for elderly fee-for-service patients with acute myocardial infarction. 


\section{Data and Methods}

\subsection{Patients}

We used data from the Cooperative Cardiovascular Project that is well described elsewhere.(9) The Cooperative Cardiovascular Project identified nearly all Medicare fee-for service beneficiaries with the principal-discharge ICD-9-CM diagnosis of 410.xx (acute myocardial infarction) excluding codes 410.x2 (subsequent care) for the period between February 1994 and July 1995. Research abstractors employed by independent contractors entered demographic, history, physical exam, hospital course, inhospital and discharge treatment data into an electronic data base. Quality checks using random reabstractions were performed on the resulting data.(10) Patients with age less than 65 years and those not residing in one of 320 metropolitan statistical areas in the continental United States were excluded.

\subsection{Treatment and Outcome Measures}

We used guidelines from the American College of Cardiology and the American Heart Association (11) and expert opinion to identify treatments recommended for patients with acute myocardial infarction based on data available in 1994. We examine 8 different treatments here: aspirin during hospitalization, aspirin at discharge, $\beta$-blocker during hospitalization, $\beta$-blocker at discharge, reperfusion during the first 24 hours of hospitalization with thrombolysis of primary percutaneous transluminal angioplasty (PTCA), coronary angiography during hospitalization, angiotensin converting enzyme (ACE) inhibitor at discharge, and smoking cessation counseling at discharge. Not every patient is a good candidate for every treatment. From the overall sample, we identified patients who were good candidates for each treatment using the standard criteria listed in Table 1. 
We also examined mortality rates. Mortality following admission was identified by linking patient records to the Health Insurance Skeletonized Eligibility Write-off (HISKEW) file. Some analyses incorporate measures of expected 30 day and 1 year mortality, which we computed using the same variables and methods used in a previously published model of mortality in Medicare patients with acute myocardial infarction from the CCP dataset.(13)

\subsection{Managed Care Activity}

In principle, many forms of managed care organizations could bring about changes in care patterns. Because we have data for health maintenance organizations (HMOs), we use HMO market share as the measure of managed care activity. We expect this to be a reasonable indication of the presence of organizations that make strong attempts to control utilization and influence provider behavior.

We used county-level estimates of the percentage of the population enrolled in HMOs that were developed for previous studies using data from the Group Health Association of America and Interstudy.(12) County level data for 1994 were combined to obtain HMO market share data for each of 320 metropolitan statistical areas (MSAs) within the United States. MSAs are a common definition of health care markets, and are frequently used in research on the effects of managed care. Managed care $(\mathrm{HMO})$ market share was classified as low $(<10 \%)$, medium $(10-30 \%)$ or high $(>30 \%)$. Breaking MSAs into three groups allows the relationship between treatment and managed care market share to be non-linear, and will limit the effects of any misestimation of managed care market share. 


\subsection{Statistical Analysis}

For each treatment, we computed the fraction of good candidates that received the treatment for markets at each level of managed care market share $(<10 \%, 10-30 \%,>30 \%)$. Differences between treatment rates in markets with the different managed care levels were compared using $\chi^{2}$ tests. The relationship between managed care activity and use of recommended treatments for acute MI among good candidates was examined using logistic regression that modeled the use of each treatment (yes or no) as a function of managed care market share, area characteristics, U.S. census division, patient demographic (age group, gender and race) admission clinical variables, and characteristics of the hospital and physician caring for the patient. Certain characteristics of a metropolitan statistical area may make it more or less attractive for HMOs to offer services, while at the same time these characteristics may be associated with use of appropriate treatments. To control for potential confounding factors we included per capita income (coded as $<\$ 15,000, \$ 15,000$ to $\$ 19,999, \$ 20,000$ to $\$ 25,000$ and $>\$ 25,000)$, population density (coded as $<2,500,2,500$ to 4,999 , 5,000-10,000 and >10,000 persons/square mile), and proportion with a college degree (coded as $<15 \%, 15 \%$ to $19 \%, 20 \%$ to $25 \%$ and $>25 \%$ ) for each metropolitan statistical area. We controlled for severity of illness using expected 30-day mortality from a previously published model that uses clinical data available at admission.(13) We controlled for admission to a teaching hospital by using data from the American Hospital Association in 1994. Hospitals with 20 or more full time residents were considered teaching hospitals. We control for hospital volume by including indicators for high volume hospitals, defined to be those with at least 50 admissions for acute myocardial infarction per year. We include an indicator for whether the patient was cared for by a cardiologist based using HCFAs UPIN file. 
Separate models were estimated for each of the eight recommended treatments. Logistic regressions naturally produce odds rations, but because odds ratios are easily misinterpreted as relative risks we converted the coefficients obtained from the logistic regression models to relative risks with 95\% confidence intervals for comparisons between high and medium managed care areas with low managed care areas.(14) We repeated the analyses after adjusting for the likelihood of being in an area with high managed care market share using the propensity score method.(15)

We investigated the relationship between HMO market share and mortality using a series of logistic models. We first estimated a model that included only the managed care variables. We then estimated models that added controls for severity of illness (expected 30 day mortality), hospital characteristics, physician specialty, and area characteristics (population density, percent college educated, per capita income and region of the United States). Finally, we wished to investigate the effects of controlling for two treatments where high HMO market share areas have higher rates of use, so we added variables indicating the use of aspirin and $\beta$-blockers.

\section{Results}

\subsection{Patient characteristics}

The baseline data set used in this study contained information on 161,962 fee-for-service elderly (age 65 years or older) Medicare patients with documented myocardial infarction. After excluding patients that resided in rural areas, 112,900 patients remained and were used to determine appropriate treatment and mortality. Patients residing in areas with high managed care activity (>30\% market share) were older and less likely to be in Killip class 1 on admission than patients residing in low managed care $(<10 \%$ market share) areas (Table 2$)$. Patients residing in high and medium managed 
care areas were more likely to be admitted to a teaching hospital than were patients residing in low managed care areas. Areas with high and medium rates of managed care had higher per-capita incomes, were more densely populated, and had a higher proportion college educated residents compared with low managed care areas. Over half of the patients from the Pacific, New England, and Mountain regions resided in high managed care areas compared to less than $5 \%$ for the four central census regions.

\subsection{Treatment Differences}

In unadjusted comparisons among patients who were good candidates for each treatment we found that patients in high-managed care areas were more likely to be appropriately treated with $\beta$ blockers during hospitalization than patients in low managed care areas (Table 3). Patients in high market share areas were also more likely to receive $\beta$-blockers at discharge and for smoking cessation counseling. In contrast, good candidates for coronary angiography or reperfusion were less likely to undergo these procedures if they resided in high managed care areas.

We then used a multivariate model that controlled for patient characteristics and demographic and other characteristics of each metropolitan area. Some of these were associated with different rates of appropriate treatment. For example, appropriate $\beta$-blocker use at discharge was greater in areas with high per capita income areas (52\% for incomes $>\$ 25,000$ per year vs. $31 \%$ for incomes $\geq$ $\$ 15,000$ per year, $\mathrm{p}<0.001$ ), high population density ( $50 \%$ for $>10,000$ persons/square mile vs. $45 \%$ for $\leq 2,500$ persons/ square mile, $\mathrm{p}<0.001)$ a high proportion of college educated residents (49\% if $>25 \%$ were college educated vs. $44 \%$ if $\leq 15 \%$ were college educated, $p<0.001$ ), and geographic area (59\% for residents of New England vs. $46 \%$ for residents from elsewhere in the United States). 
Patients were more likely to receive $\beta$-blockers at discharge if they were admitted to a teaching (53\% vs $44 \%$ ) or high volume hospital (48\% vs $40 \%$ ), or were cared for by a cardiologist (51\% vs $43 \%$, all $\mathrm{p}<0.001)$.

After adjusting for area-related characteristics, U.S. census division, age, gender, race, hospital characteristics, physician specialty, and 30-day predicted mortality, some of the differences in use for good treatment candidates persisted between high and low managed care areas (Figure 1). Compared with patients residing in areas with low managed care activity, patients residing in high managed care areas were more likely to receive $\beta$-blockers (16\% greater use, $95 \%$ CI $7 \%$ to $24 \%)$ and aspirin (4\% greater use, $95 \%$ CI $1 \%$ to $6 \%$ ) during hospitalization. These relative uses correspond to a number needed to treat of 33 for aspirin and 13 for $\beta$-blockers, indicating that there was one additional patient treated with aspirin for every 33 good aspirin candidates in high compared to low managed care areas, and one more per 13 good $\beta$-blocker candidates. The difference in treatment between high and low managed care areas persisted at discharge for $\beta$-blockers (18\%, 95\% CI 6\% to 29\%) and aspirin (5\% greater for high managed care areas, $95 \%$ CI $2 \%$ to $7 \%$ ). These patterns are consistent with better treatment in higher managed care areas.

We found no significant differences in the use of reperfusion, angiography, smoking cessation counseling at discharge, or ACE inhibitor use at discharge. Nonetheless, some of the trends we observed in the data suggest continued attention. In particular, we observed almost statistically significant lower use of angiography among good candidates (recurrent ischemia or shock) in high managed care areas $(-7 \%, 95 \%$ CI $1 \%$ to $-14 \%)$. This lower use is equivalent to one less angiogram performed for every 31 patients that were good candidates for angiography. Among all patients, high managed care areas used significantly less angiography $(-6 \%, 95 \% \mathrm{CI}-2 \%$ to $-10 \%)$. Results for 
reperfusion also suggest less use in high managed care areas, while the results for smoking cessation counseling suggest improved care with increases in HMO market share.

If HMO market share is correlated with other area characteristics, our results could be biased.

One method of adjusting for confounding in the estimates of the effect of HMOs is the use of propensity scoring. For each patient, we computed the propensity for residing in a high managed care area, and then included this propensity score in the model as a way of adjusting for potential confounding. Similar results were observed. After adjustment for propensity to reside in a high managed care area, the greater relative use of treatments persisted for high managed care compared to low managed care areas for $\beta$-blockers during hospitalization $(16 \%, 95 \% \mathrm{CI}: 8 \%$ to $23 \%), \beta$-blockers at discharge $(17 \%, 95 \%$ CI: $7 \%$ to $26 \%$ ), and aspirin during hospitalization (2\%, CI: $0 \%$ to $4 \%$ ). Differences in coronary angiography use for patients with recurrent angina or shock were slightly larger with the propensity score adjustment (9\% lower use in high relative to low managed care areas; $95 \%$ CI 2\% to 15\%).

\subsection{Mortality Differences}

Mortality at 30 days among all patients in the sample was $18.6 \%$. Unadjusted 30-day mortality was slightly lower for patients residing in high (18.0\%) and medium (18.5\%) managed care areas compared to patients in low-managed care areas $(19.6 \%, \mathrm{p}<0.0001)$. Mean expected 30-day mortality using clinical data at admission (13), however, was higher for patients from high (19.3 \pm $17.5 \%)$ than for medium $(18.9 \pm 17.7 \%)$ or low $(18.3 \pm 18.0 \%)$ managed care areas $(\mathrm{p}<0.0001)$.

Figure 2 plots results from a series of models of mortality rates. The first two points are the relative risk for high and medium market share areas from a model that uses only HMO market share controls. Here, patients in high HMO market share areas have relative risk of mortality about 8 points lower than those in the lowest market share areas. Relative survival differences increase after 
adjustment for clinical characteristics at admission and persist after controlling for hospital characteristics and physician specialty. But, when region of the U.S. and area characteristics (population density, \% with college education, per capita income) are included, the differences in mortality between high and low market share areas are not longer evident (relative risk $1.02,95 \%$ CI 0.95 to 1.10 ).

\section{Discussion}

This analysis of elderly Medicare beneficiaries with fee-for-service insurance found differences in the treatment of acute myocardial infarction according to the level of managed care market share. Fee-for-service patients residing in areas with high managed care market share were more likely to be appropriately treated with aspirin and $\beta$-blockers, consistent with better care. On the other hand, these patients were (almost significantly) less likely to receive appropriate coronary angiography than were patients residing in areas with low managed care market share. We found no strong differences in the use of reperfusion at 24 hours, smoking cessation counseling at discharge, and ACE inhibitor use at discharge.

The differences in aspirin, $\beta$-blockers, and angiography among fee-for-service patients suggest that the presence of managed care can have widespread effects on area treatment patterns and the quality of care, sufficient to influence care for patients not enrolled in managed care plans. These results are consistent with other studies that suggest that managed care can have broad effects on care delivery. High levels of managed care have been associated with lower health care expenditures for fee-forservice patients. In a recent study of fee-for-service Medicare patients, for example, an increase in the managed care market share of $10 \%$ to $20 \%$ was associated with a $2 \%$ decrease in Part A fee-for-

service expenditures and a 1.5\% decrease in Part B fee-for-service expenditures.(2) But, these studies 
have not been clear about the ability of managed care to influence treatment patterns specifically, or about the quality implications of any managed-care induced changes in treatments.

There are several mechanisms by which managed care activity could influence the care of patients with fee-for-service insurance. First, managed care could alter the availability of services such as coronary angiography laboratories. If an increase in managed care activity reduced the number of available laboratories, the overall use of angiography could decline regardless of the patient's insurance status. Past studies have demonstrated that increases in HMO market share are associated with reductions in the availability of costly medical services $(3,4,16)$ and changes in the number and type of practicing physicians.(17)

Managed care may also influence the care of fee-for-service patients by influencing physician practice patterns. Many physicians treat both managed care and fee-for-service patients. In a survey from 1996, managed care enrollees comprised 25\% (median) of active patients treated by U.S. physicians that had at least 1 managed care contract.(18) Physicians may find it difficult or undesirable to vary their treatment patterns for different patients. As managed care grows and exerts more and more influence over physician practices, even fee-for-service patients may be treated differently. Physicians who have only fee-for-service patients may be indirectly influenced by managed care activity if they adopt the practice patterns of other local physicians.(6)

Managed care organizations have incentives to improve guideline compliance among physicians and hospital personnel. One popular measure of the quality of managed care organizations is the Health Plan Employer Data and Information Set (HEDIS) developed by the National Committee for Quality Assurance.(19, 20) The measures from HEDIS are used to aid employers in choosing health plans for their employees. One of the new HEDIS measures (instituted after the data for our study was collected) is the fraction of patients discharged on a $\beta$-blocker following acute myocardial infarction. In 
a recent survey of managed care physician groups, $85 \%$ had instituted methods to improve guideline compliance.(21)

Our findings of managed care effects on treatment of fee-for-service patients are consistent with past retrospective studies that directly compared patients in HMOs with those in fee-for-service for the treatment of acute coronary syndromes. In an analysis of Medicare beneficiaries with acute myocardial infarction from Minnesota, patients with managed care insurance received more appropriate aspirin therapy ( $88 \%$ vs. $83 \%$ p=0.03) than those with fee-for-service insurance.(7) In a review by the RAND Corporation, Medicare patients with acute myocardial infarction in three HMOs were compared to a fee-for-service sample using process of care measures developed by an expert panel.(8) There was greater compliance with process of care measures of the provider's clinical assessment and treatment for the HMO patients. However, fee-for-service patients received more appropriate procedures and diagnostic tests. Similar findings were noted in a report of patients from the Global Unstable Angina Registry and Treatment Evaluation (GUARANTEE) study.(22) Patients in HMO's were 10\% more likely to be discharged on aspirin, and $14 \%$ more likely to be discharged on $\beta$-blockers (relative risk 1.14), while fee-for-service patients were more likely to receive angiography.

A previous report of patients with acute coronary syndromes did not find a difference in survival between Medicare patients with fee-for-service and those with managed care insurance. (22) Our study, perhaps because of its large size, found a small difference in mortality favoring areas with high managed care market share when no adjustments were made for clinical, hospital or area characteristics. Because patients from high managed care areas were more ill on admission than patients from low managed care areas adjustment for clinical variables increased the survival difference between high and low managed care areas. Patients in high managed care areas were more likely to be admitted to a teaching hospital, which have been shown to have better outcomes for patients in general, $(23,24)$ 
and acute MI in particular, (25) when compared with non-teaching hospitals. Both admission to a high volume hospital (26) and management by a cardiologist (27) have been associated with better survival following acute myocardial infarction in studies using the same datasets as in our analysis. However, adjustment for hospital characteristics and specialty of treating physician did not alter the relationship between high managed care areas and survival. Past studies have documented regional differences in mortality for acute myocardial infarction. (28) Our study also found that community characteristics consistent with high socioeconomic status (e.g. per capita income) were associated with both more managed care penetration and improved survival. After controlling for these area characteristics and the region of the U.S., the differences in survival between high and low managed care areas were no longer apparent.

This study has several important limitations. Because the detailed clinical data used for this study were from a single time period (1994-1995) we are unable to prove that a change in the level of managed care market share changes the care of fee-for-service patients. Such a study would require several observations over time that are of similar detail to the measures in the Cooperative Cardiovascular Project. Because the metropolitan statistical areas are not randomized to different levels of managed care activity it is possible that certain unmeasured area-related variables have confounded the results.

In summary, our study found that Medicare beneficiaries with fee-for-service insurance and who resided in areas with high managed care activity were more likely to receive appropriate aspirin and $\beta$ blockers, and less likely to receive appropriate coronary angiography following admission for myocardial infarction than were patients residing in areas with low managed care activity. These results suggest that effects of managed care are not limited to patients enrolled in managed care plans. 


\section{References}

1. Miller RH, Luft HS. Managed care plan performance since 1980. A literature analysis. Jama. 1994;271(19):1512-9.

2. Baker LC. Association of managed care market share and health expenditures for fee-forservice Medicare patients . Jama. 1999;281(5):432-7.

3. Baker LC, Wheeler SK. Managed care and technology diffusion: the case of MRI. Health Aff (Millwood). 1998;17(5):195-207.

4. Cutler D, Sheiner L. Manged care and the growth of medical expenditures. In: Garber A, ed. Frontiers in Health Policy Research. Cambirdge, MA: MIT Press; 1998:77-116.

5. Gaskin DJ, Hadley J. The impact of HMO penetration on the rate of hospital cost inflation, 1985-1993. Inquiry. 1997;34(3):205-16.

6. Phelps CE. Diffusion of information in medical care. J Econ Perspect. 1992;6(3):23-42.

7. Soumerai SB, McLaughlin TJ, Gurwitz JH, Pearson S, Christiansen CL, Borbas C, et al. Timeliness and quality of care for elderly patients with acute myocardial infarction under health maintenance organization vs fee-for- service insurance. Arch Intern Med. 1999;159(17):2013-20.

8. Carlisle DM, Siu AL, Keeler EB, McGlynn EA, Kahn KL, Rubenstein LV, et al. HMO vs feefor-service care of older persons with acute myocardial infarction. Am J Public Health. 1992;82(12):1626-30.

9. Marciniak TA, Ellerbeck EF, Radford MJ, Kresowik TF, Gold JA, Krumholz HM, et al. Improving the quality of care for Medicare patients with acute myocardial infarction: results from the Cooperative Cardiovascular Project . Jama. 1998;279(17):1351-7.

10. Huff ED. Comprehensive reliability assessment and comparison of quality indicators and their components. J Clin Epidemiol. 1997;50(12):1395-404. 
11. Gunnar RM, Bourdillon PD, Dixon DW, et al., ACC/AHA guidelines for the early management of patients with acute myocardial infarction. A report of the American College of Cardiology/American Heart Association Task Force on Assessment of Diagnostic and Therapeutic Cardiovascular Procedures (subcommittee to develop guidelines for the early management of patients with acute myocardial infarction). Circulation 1990;82:664-707.

12. Baker LC. The effect of HMOs on fee-for-service health care expenditures: evidence from Medicare. J Health Econ. 1997;16(4):453-81.

13. Normand ST, Glickman ME, Sharma RG, McNeil BJ. Using admission characteristics to predict short-term mortality from myocardial infarction in elderly patients. Results from the Cooperative Cardiovascular Project . Jama. 1996;275(17):1322-8.

14. Zhang J, Yu KF. What's the relative risk? A method of correcting the odds ratio in cohort studies of common outcomes. Jama. 1998;280(19):1690-1.

15. D. Agostino RB J. Propensity score methods for bias reduction in the comparison of a treatment to a non-randomized control group. Stat Med. 1998;17(19):2265-81.

16. Cutler D, McClellan M. The Determinants of Technological Change in Heart Attack Treatment.: NBER Working Paper Series No. 5751. Cambridge, Mass: National Bureau of Economic Research; 1996.

17. Escarce J, Polsky D, Wozniak G, Pauly M, Kletke P. HMO Penetration and the Practice Location Choices of New Physicians: A Study of Large Metropolitan Areas in the US. . Santa Monica, CA: RAND; 1998.

18. Terry K. New survey results. Managed-care participation--and income--keep rising. Med Econ. 1996;73(19):196-8, 201, 205-8. 
19. Himmelstein DU, Woolhandler S, Hellander I, Wolfe SM. Quality of care in investor-owned vs not-for-profit HMOs. Jama. 1999;282(2):159-63.

20. Appleby C. HEDIS (Health Plan Employer Data and Information Set): managed care's emerging gold standard. Manag Care. 1995;4(2):19-24.

21. Fang E, Mittman BS, Weingarten S. Use of clinical practice guidelines in managed care physician groups . Arch Fam Med. 1996;5(9):528-31.

22. Every NR, Cannon CP, Granger C, Moliterno DJ, Aguirre FV, Talley JD, et al. Influence of insurance type on the use of procedures, medications and hospital outcome in patients with unstable angina: results from the GUARANTEE Registry. Global Unstable Angina Registry and Treatment Evaluation. J Am Coll Cardiol. 1998;32(2):387-92.

23. Allison JJ, Kiefe CI, Weissman NW, et al., Relationship of hospital teaching status with quality of care and mortality for Medicare patients with acute MI. JAMA 2000;284:1256-1262.

24. Taylor DH, Jr., Whellan DJ, Sloan FA. Effects of admission to a teaching hospital on the cost and quality of care for Medicare beneficiaries . N Engl J Med. 1999;340(4):293-9.

25. Rosenthal GE, Harper DL, Quinn LM, Cooper GS. Severity-adjusted mortality and length of stay in teaching and nonteaching hospitals. Results of a regional study . Jama. 1997;278(6):485-90.

26. Thiemann DR, Coresh J, Oetgen WJ, Powe NR. The association between hospital volume and survival after acute myocardial infarction in elderly patients. N Engl J Med 1999;340:1640-1648.

27. Jollis JG, DeLong ER, Peterson ED, et al. Outcome of acute myocardial infarction according to the specialty of the admitting physician. N Engl J Med 1996;335:1880-1887.

28. Guadagnoli E, Hauptman PJ, Ayanian JZ, Pashos CL, McNeil BJ, Cleary PD. Variation in the use of cardiac procedures after acute myocardial infarction. N Engl J Med 1995;333:573-578. 
Table 1: Definitions of Good Candidates for Selected Acute MI Treatments

\section{Aspirin during hospitalization}

All acute MI patients without an allergy to aspirin, history of bleeding, evidence of bleeding on admission or during hospitalization, history of internal bleeding, coagulopathy (history of bleeding disorder), platelet count $<100$ x 109/L, warfarin on admission, chronic liver disease, peptic ulcer disease, hemotacrit $<30 \%$ or hemoglobin $<100 \mathrm{~g} / \mathrm{L}$, highest creatinine $>265 \mu \mathrm{mol} / \mathrm{L}(3 \mathrm{mg} / \mathrm{dl})$, or terminal illness.

\section{$\beta$-Blocker during hospitalization}

All acute MI patients without systolic blood pressure $<100 \mathrm{mmHg}$ at admission, shock, conduction disorder including second, or third-degree heart block, bifasicular or trifasicular block, wheezing during hospitalization, bradycardia $<50$ beats per minute on admission, any left ventricular ejection fraction $<50 \%$, pulmonary edema or CHF unless ejection fraction $>50 \%$, history of chronic obstructive pulmonary disease, dementia, antidepressant on admission, insulin on admission, or terminal illness.

\section{Reperfusion with thrombolytic therapy or primary PTCA}

Patients with acute MI and ST elevation without a time from chest pain to admission > 6 hours, history of bleeding, active internal bleeding, coagulopathy, history of stroke, trauma in the last 4 weeks, surgery or biopsy in the last 8 weeks, cardiac arrest, warfarin on admission, refusal of thrombolysis, systolic blood pressure $>180 \mathrm{mmHg}$ or diastolic blood pressure $>110 \mathrm{mmHg}$, age greater than 80 years, peptic ulcer disease, chronic liver disease, or terminal illness.

\section{Angiography during admission}

All patients with acute MI and recurrent chest pain more than 48 hours after admission, or shock, but without a highest creatinine of $>176 \mu \mathrm{mol} / \mathrm{L}(2 \mathrm{mg} / \mathrm{dl})$, or terminal illness.

\section{Aspirin prescribed at discharge}

All acute MI patients discharged alive without allergy to aspirin, history of bleeding, evidence of bleeding on admission or during hospitalization, history of internal bleeding, coagulopathy (history of bleeding disorder), platelet count $<100 \times 109 / \mathrm{L}$, warfarin at discharge, chronic liver disease, peptic ulcer disease, hemotacrit $<30 \%$ or hemoglobin $<100 \mathrm{~g} / \mathrm{L}$, highest creatinine $>265 \mu \mathrm{mol} / \mathrm{L}(3 \mathrm{mg} / \mathrm{dl})$, or terminal illness.

\section{B-Blocker prescribed at discharge}

All acute MI patients discharged alive without systolic blood pressure $<100 \mathrm{mmHg}$ at discharge, shock, conduction disorder including second, or third-degree heart block, bifasicular or trifasicular block, wheezing during hospitalization, bradycardia $<50$ beats per minute on discharge, any left ventricular ejection fraction $<50 \%$, pulmonary edema or CHF unless ejection fraction $>50 \%$, history of chronic obstructive pulmonary disease, dementia, antidepressant at discharge, insulin on admission, or terminal illness. 
Table 1, continued

\section{ACE inhibitor prescribed at discharge}

All patients with acute MI and left ventricular ejection fraction < 40\% discharged alive without allergy or intolerance to ACE inhibitor, systolic blood pressure at discharge $<100 \mathrm{mmHg}$, aortic stenosis, highest creatinine $>176 \mu \mathrm{mol} / \mathrm{L}(2 \mathrm{mg} / \mathrm{dl})$, or terminal illness.

\section{Smoking cessation counseling at discharge}

All patients with acute MI discharged alive that were current smokers at the time of discharge. 
Table 2. Patient and Regional Characteristics and Managed Care Market Share.

\section{Managed Care Market Share}

\begin{tabular}{|c|c|c|c|c|}
\hline Characteristic & $\begin{array}{c}<10 \% \\
(\mathrm{~N}=16,951)\end{array}$ & $\begin{array}{c}10 \%-30 \% \\
(\mathrm{~N}=72,074)\end{array}$ & $\begin{array}{c}>30 \% \\
(\mathrm{~N}=\mathbf{2 3 , 8 7 5 )}\end{array}$ & $P$ value \\
\hline \multicolumn{5}{|l|}{ Demographic } \\
\hline Age (years) & $75.9 \pm 7.3$ & $76.4 \pm 7.4$ & $76.7 \pm 7.4$ & $<0.001$ \\
\hline Male (\%) & 51.1 & 50.7 & 51.2 & 0.20 \\
\hline White race $(\%)$ & 88.6 & 89.5 & 87.2 & $<0.001$ \\
\hline Prior CHF (\%) & 20.8 & 21.8 & 22.4 & 0.03 \\
\hline Diabetes mellitus (\%) & 30.6 & 31.0 & 29.6 & $<0.001$ \\
\hline Hypertension (\%) & 62.2 & 62.8 & 61.3 & $<0.001$ \\
\hline Prior MI (\%) & 28.6 & 28.9 & 29.0 & 0.8 \\
\hline Prior angioplasty (\%) & 7.1 & 6.6 & 6.8 & 0.05 \\
\hline Prior bypass surgery $(\%)$ & 12.3 & 12.3 & 12.7 & 0.11 \\
\hline $\begin{array}{l}\text { Heart rate }>100 \text { beats per minute } \\
(\%)\end{array}$ & 24.6 & 25.1 & 24.1 & 0.01 \\
\hline Anterior infarction (\%) & 42.9 & 42.2 & 41.5 & $<0.001$ \\
\hline Killip class (\%) & & & & $<0.001$ \\
\hline 1 & 65.1 & 62.8 & 63.1 & \\
\hline 2 & 9.4 & 9.1 & 8.8 & \\
\hline 3 & 24.3 & 27.0 & 26.9 & \\
\hline 4 & 1.1 & 1.2 & 1.2 & \\
\hline Admission to teaching hosp. (\%) & 16 & 29 & 21 & $<0.001$ \\
\hline Admission to high volume hosp & 76 & 80 & 76 & $<0.001$ \\
\hline Treated by cardiologist & 37 & 35 & 37 & $<0.001$ \\
\hline Area Per-capita income (\$) & $\begin{array}{l}18,100 \pm \\
2,600\end{array}$ & $\begin{array}{l}21,500 \pm \\
3,500\end{array}$ & $22,500 \pm 3,500$ & $<0.001$ \\
\hline $\begin{array}{l}\text { Area Population with college } \\
\text { education }(\%)\end{array}$ & $18.0 \pm 4.6$ & $21.1 \pm 4.7$ & $25.1 \pm 6.1$ & $<0.001$ \\
\hline $\begin{array}{l}\text { Area Population density (persons } \\
\text { per square mile) }\end{array}$ & $\begin{array}{c}2,490 \pm \\
1,600 \\
\end{array}$ & $\begin{array}{c}12,100 \pm \\
19,900\end{array}$ & $11,780 \pm 7,900$ & $<0.001$ \\
\hline
\end{tabular}


Managed Care Market

Share

\% Use (total N)

\begin{tabular}{|c|c|c|c|c|c|}
\hline Treatment & $\begin{array}{c}\text { Number of } \\
\text { Good } \\
\text { Candidates }\end{array}$ & $\begin{array}{c}\text { Overall } \\
\text { Use } \\
(\%)\end{array}$ & $<10 \%$ & $\begin{array}{l}10 \%- \\
30 \%\end{array}$ & $>30 \%$ \\
\hline \multicolumn{6}{|l|}{ During Hospitalization } \\
\hline Aspirin & 44,268 & 84.4 & $\begin{array}{c}84.1 \\
(6,376)\end{array}$ & $\begin{array}{c}84.3 \\
(27,902)\end{array}$ & $\begin{array}{c}85.0 \\
(9,990)\end{array}$ \\
\hline$\beta$-Blocker* & 15,809 & 56.4 & $\begin{array}{c}50.3 \\
(2,161)\end{array}$ & $\begin{array}{c}56.4 \\
(9,777)\end{array}$ & $\begin{array}{c}59.8 \\
(3,871)\end{array}$ \\
\hline $\begin{array}{l}\text { Thrombolytic therapy or } \\
\text { primary angioplasty } \\
\text { within } 24 \text { hours of } \\
\text { admission* }\end{array}$ & 5,309 & 70.8 & $\begin{array}{l}72.9 \\
(922)\end{array}$ & $\begin{array}{c}71.1 \\
(3,281)\end{array}$ & $\begin{array}{c}66.6 \\
(1,106)\end{array}$ \\
\hline Coronary angiography* & 27,442 & 44.7 & $\begin{array}{c}50.3 \\
(4,742)\end{array}$ & $\begin{array}{c}45.4 \\
(17,639)\end{array}$ & $\begin{array}{c}36.9 \\
(5,061)\end{array}$ \\
\hline \multicolumn{6}{|l|}{ Treatment at Discharge } \\
\hline Aspirin & 32,587 & 76.5 & $\begin{array}{c}78.4 \\
(4,604)\end{array}$ & $\begin{array}{c}75.6 \\
(20,576)\end{array}$ & $\begin{array}{c}78.0 \\
(7,407)\end{array}$ \\
\hline$\beta$-Blocker* & 14,131 & 48.3 & $\begin{array}{c}42.3 \\
(1,896)\end{array}$ & $\begin{array}{c}48.2 \\
(8,742)\end{array}$ & $\begin{array}{c}51.5 \\
(3,493)\end{array}$ \\
\hline ACE inhibitor & 9,210 & 60.6 & $\begin{array}{c}58.3 \\
(1,327)\end{array}$ & $\begin{array}{c}61.0 \\
(6,098)\end{array}$ & $\begin{array}{c}60.7 \\
(1,785)\end{array}$ \\
\hline $\begin{array}{l}\text { Smoking cessation } \\
\text { counseling }\end{array}$ & 10,627 & 39.4 & $\begin{array}{c}38.6 \\
(1,893)\end{array}$ & $\begin{array}{c}38.3 \\
(6,728)\end{array}$ & $\begin{array}{c}43.7 \\
(2,006)\end{array}$ \\
\hline
\end{tabular}

$* \mathrm{P}=0.001$ for differences across groups and for differences between high and low market share area 
Figure 1: Area Managed Care Activity and Use of Appropriate Treatments for Elderly AMI Patients

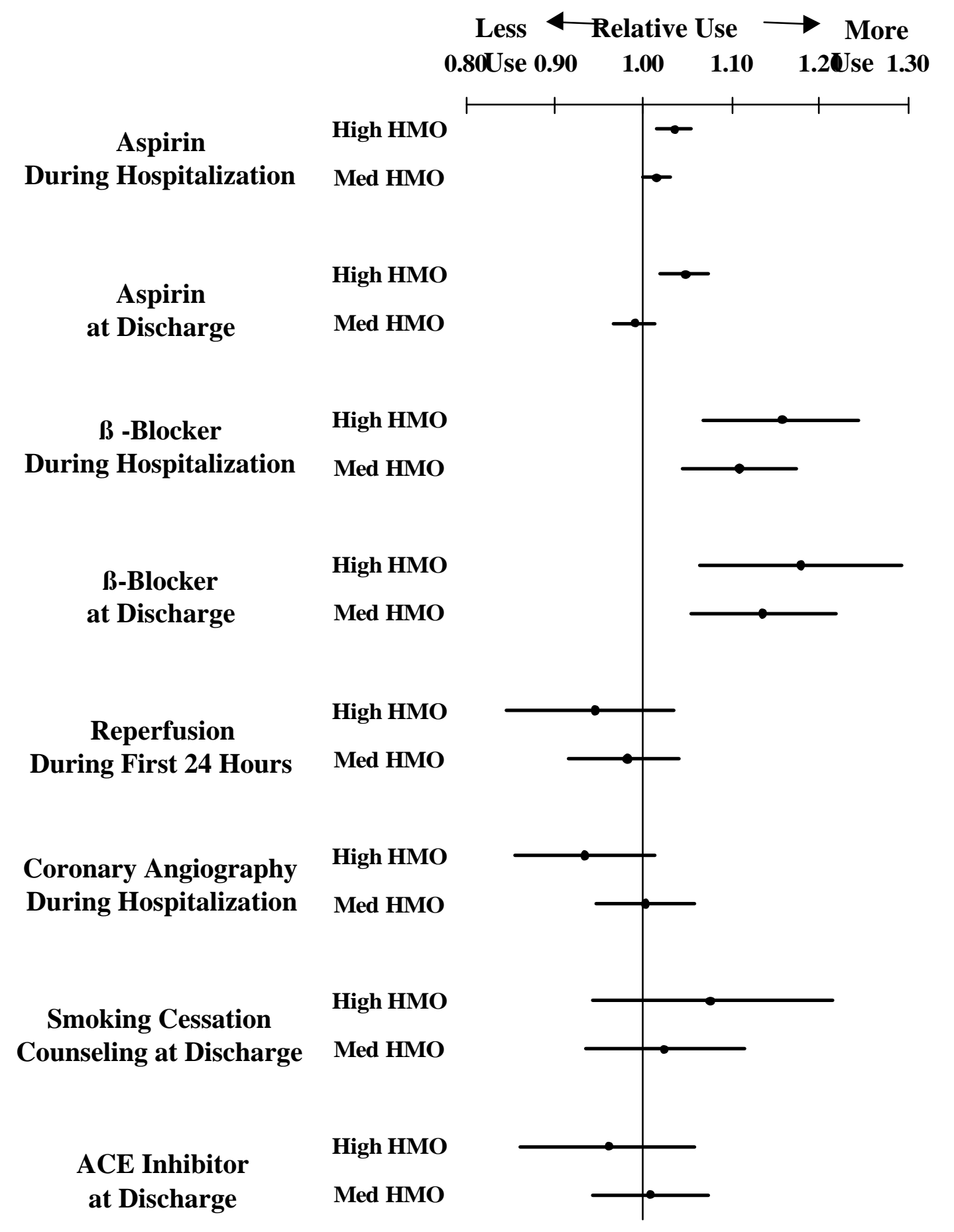

The adjusted relative risks and 95\% confidence intervals for the use of recommended treatments in good candidates are displayed for high and medium managed care (HMO) market share areas relative to low managed care market share areas. Values greater than 1.0 indicate greater use of therapies. The relative risks have been adjusted for age, gender, race, per-capita income, population density, mean education level, hospital characteristics, physician specialty, census region of the United States, and severity of illness. (13) 
Figure 2: Area Managed Care Activity and Relative Risk of 30 Day Mortality

No Adjustment

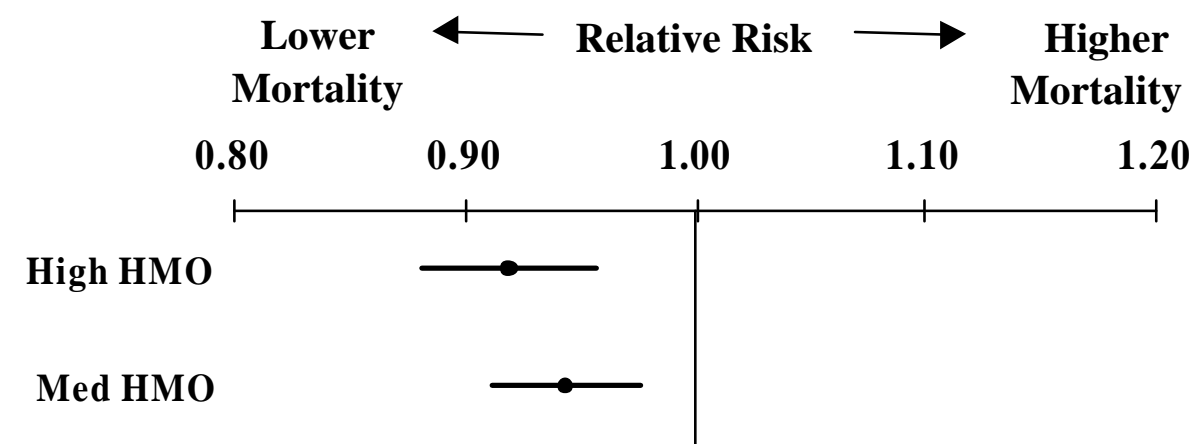

\section{Adjustment for Severity of Illness}

\author{
Above Plus Hospital \\ Teaching Status \\ and Volume
}

High HMO $\longrightarrow$

Med HMO

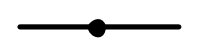

High HMO $\longrightarrow$

Med HMO

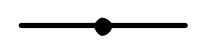

\section{Above Plus Physician Specialty}

\section{High HMO}

Med HMO

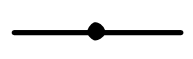

\section{High HMO}

Above Plus Area Characteristics

\section{Med HMO}

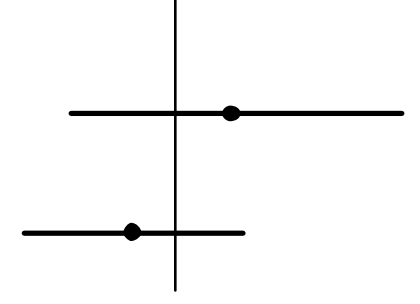

The relative risks and 95\% confidence intervals for death at 30 days are shown for patients from high and medium managed care (HMO) market share areas compared to low managed care areas. Values greater than 1.0 indicate higher mortality. The unadjusted risk of death is lowest in high managed care areas. After adjustment for severity of illness (13) the differences increase and persist after including hospital and physician characteristics. When area characteristics are included (region, population density, $\%$ with college education, per capita income) the differences are no longer apparent. The c statistics (measures of area under the receiver operating curve) for the five models are 0.51 (no adjustment), 0.76 (+severity of illness), 0.76 (+ hospital characteristics), 0.76 (+physician characteristics), and 0.77 (+ area characteristics). 